\title{
On the interaction between linguistic and pictorial systems in the absence of semantic mediation: Evidence from a priming paradigm
}

\author{
MARILYN CHAPNIK SMITH \\ University of Toronto, Scarborough, Ontario, Canada \\ NACHSHON MEIRAN \\ Ben-Gurion University of the Negev, Beer Sheva, Israel \\ and \\ DEREK BESNER \\ University of Waterloo, Waterloo, Ontario, Canada
}

\begin{abstract}
Use of the letter search task in the context of the priming paradigm has proved to be an invaluable tool for the investigation of the strategic control of processes involved in word recognition. In particular, previous findings that letter search on a prime word interferes with the priming of semantically/ associatively related targets, but not with the priming of either identical or morphologically related targets, suggests that letter search may selectively interfere with semantic processing, leaving other levels of processing intact. In the present experiments, this investigation was extended by exploring the priming of pictures following letter search of either a same-concept word (repetition priming) or a semantically/associatively related word (semantic priming). There was significant repetition priming of picture categorization following both silent reading and letter search of the prime word (Experiments 1 and 2). In contrast, semantic priming of pictures was found only following silent reading of the prime; there was no semantic priming following letter search of the prime (Experiment 2). This pattern of results suggests that focusing attention at the letter level during prime processing selectively attenuates activation of the semantic system by the prime. It does not prevent the spread of activation between the lexical and pictogen levels of representation of a given concept.
\end{abstract}

The semantic priming paradigm has proved to be an invaluable tool for investigating the organization of the cognitive network. Its use is based on the rationale that if target processing is facilitated by the prior presentation of a prime, the prime must have activated some component of the target representation. Although there has been some dispute about whether cognitive representations are best conceptualized as being local or distributed, and consequently about whether facilitation results from a spread of activation between nodes (e.g., Collins \& Loftus, 1975; Posner \& Snyder, 1975), or from an overlap of semantic features shared by prime and target (Masson, 1991), the underlying rationale that priming results from the prior activation of some component of the target's representation remains valid. Similarly, the rationale is not negated by the suggestion that some aspects of the facilitation observed in semantic priming may result from processes that

This work was supported by Natural Sciences and Engineering Research Council of Canada Grant OGPIN012 to M.C.S. and a Rotman Fellowship to N. Merian. We thank Morris Moscovitch and Stefan Kohler for use of their picture files, and Marilyn Ziegler for assistance in programming the studies. Address correspondence to M. C. Smith, Life Sciences Division, University of Toronto, Scarborough, ON, MIC 1 A4 Canada (e-mail: smith@scar.utoronto.ca). occur postlexically (Neely \& Keefe, 1989; Ratcliff \& McKoon, 1997).

Although there has been some debate about whether semantic priming depends on semantic processes or can be explained entirely by lexical associations, there is now considerable evidence for semantic involvement. For example, several investigators have demonstrated the priming of targets when they are preceded by primes that are semantically, but not associatively, related, thereby localizing the priming effects at the semantic level (e.g., Chiarello, Burgess, Richards, \& Pollock, 1990; Chiarello \& Richards, 1992; Fischler, 1977; Hines, Czerwinski, Sawyer, \& Dwyer, 1986; Lupker, 1984; Moss, Ostrin, Tyler, \& Marslen-Wilson, 1995; Schreuder, Flores d'Arcais, \& Glanzenborg, 1984; Seidenberg, Waters, Sanders, \& Langer, 1984). In addition, simulation studies have been able to closely mimic semantic priming effects using only measures of semantic similarity (Lund, Burgess, \& Atchley, 1995).

Whereas the semantic priming task per se has been useful for mapping out the structure and organization of the cognitive network, manipulation of the way in which the prime is processed has been an important tool for studying cognitive control mechanisms. In particular, such manipulation has helped to differentiate the processes that 
occur automatically during word recognition from those which may be strategically controlled. One task that has been employed extensively in this regard is the letter search task, in which subjects are instructed to attend to the letter level during prime processing - for example, by asking subjects whether the first letter in the prime is a vowel or a consonant (Bentin, Smith, \& Spalek, 1997), or whether the letter replicated above the prime word is present in the prime (e.g., Smith, 1979). Regardless of the way in which attention is directed to the letter level, the effect is the same: In contrast to the robust semantic priming that typically occurs following the presentation of a semantically/associatively related prime, semantic priming is reduced or eliminated following letter search of the prime (e.g., Besner, Smith, \& MacLeod, 1990; Friedrich, Henik, \& Tzelgov, 1991; Henik, Friedrich, \& Kellogg, 1983; Henik, Friedrich, Tzelgov, \& Tramer, 1994; Hoffman \& MacMillan, 1985; Kaye \& Brown, 1985; Smith, 1979; Smith, Meiran, \& Besner, 1996;
Smith, Theodor, \& Franklin, 1983; Stolz \& Besner, 1997, 1998).

The elimination or reduction of semantic priming following letter search of the prime indicates that focusing attention at the letter level may interfere with activation of the semantic system. To better understand how interference may occur, consider the simple model of word recognition presented in the left-hand side of Figure 1. According to this model, information about a word can be represented at several different levels: the letter level, the lexical level, and the conceptual level. When a word is read, visual analysis initiates bottom-up activation of letter level representations at the orthographic level, followed by activation of whole word information at the lexical level, and then activation of conceptual information at the semantic level. In turn, activation of a given level produces top-down feedback to the lower level, as postulated in the interactive activation model of McClelland and Rumelhart (1981).

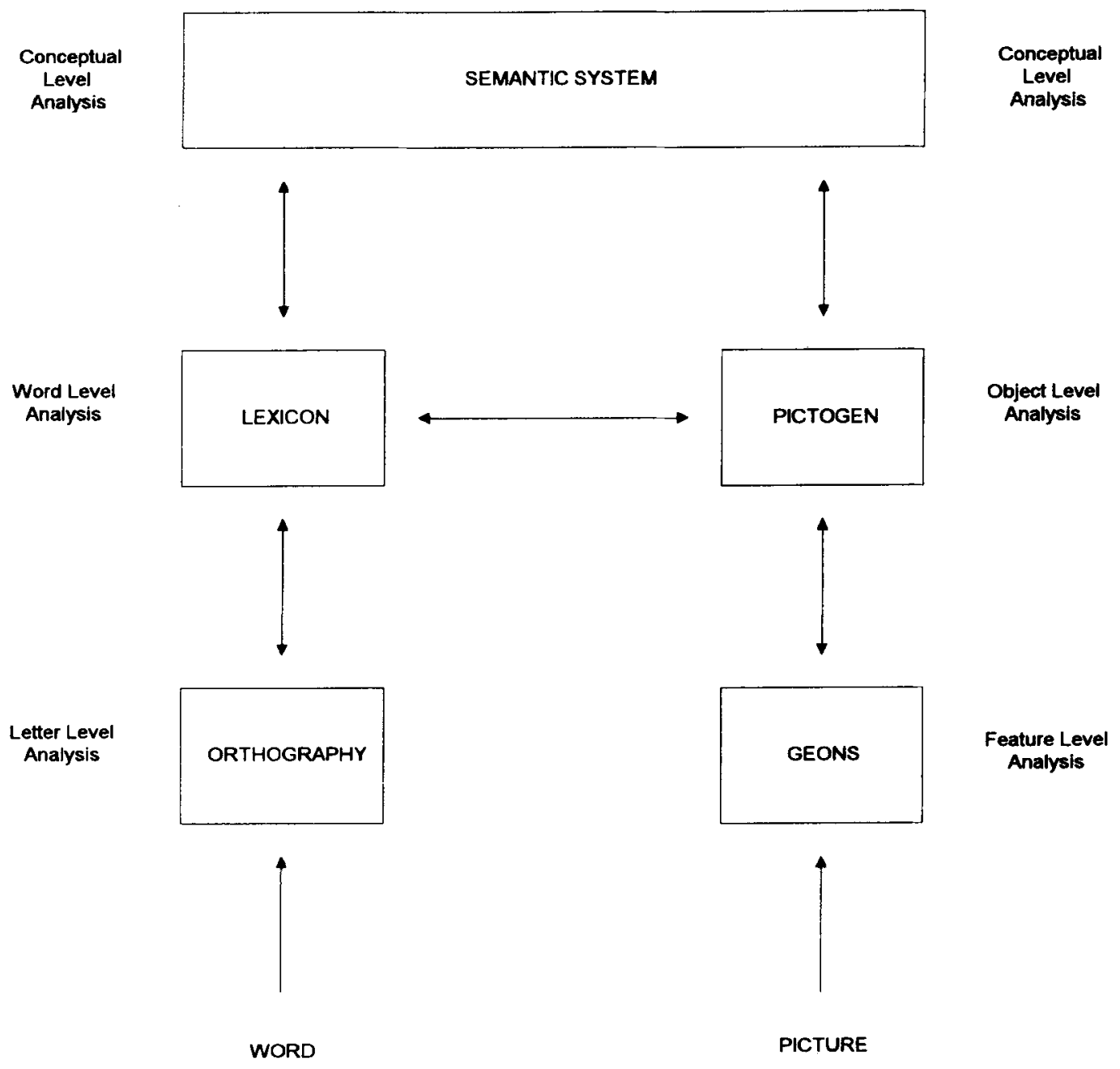

Figure 1. Simple model of word and picture processing. 
The elimination or reduction of semantic priming following letter search of the prime suggests that input to the semantic system is impaired by letter search. In contrast, two findings suggest that letter search does not impede lexical activation. The first finding comes from experiments on repetition priming, in which prime and target are the same word. In contrast to the elimination of semantic priming of related targets (e.g., BREAD-BUTTER) following letter search in the prime, repetition priming of identical targets (e.g., BUTTER-BUTTER) remains, provided that the stimulus is a real word. There is no repetition priming of nonword targets following letter search of a nonword prime (e.g., NURTE-NURTE) (Friedrich et al., 1991, Experiment 2). The second finding is based on a comparison of speed of letter search through words and nonwords: Subjects can search a letter string more rapidly if it is a real word than if it is a nonword, even when sequential redundancy is controlled (Besner et al., 1990; Krueger \& Weiss, 1976). Since the only difference between words and nonwords is that words have a lexical representation whereas nonwords do not, the superior processing of words over nonwords in both situations can be explained in terms of activation of the lexicon, which produces top-down feedback from the lexical level to the letter level of representation. This additional letter level activation of words facilitates the processing of the words' letters, resulting in both a faster search through words than through nonwords, and in the repetition priming of target words that are the same as the previously presented prime.

The impairment of semantic processing during letter search may be explained in terms of attentional demands. Given that the typical goal of reading is to attain meaning, we may assume that whereas some resources are needed for implicit letter processing, most resources are employed for semantic processing. In contrast, when one of the letter search tasks is used, thereby requiring explicit letter identification, increased resources are deployed to the orthographic level. Given limited attentional resources (see, e.g., Anderson, 1976, 1983; Kahneman, 1973; Navon \& Gopher, 1979), such deployment would decrease the resources available for semantic processing. The preservation of lexical processing despite the impairment of semantic processing suggests that the resources needed for letter-level processing may encompass lexical-level activation as well. This policy of resource allocation is plausible if the benefit that accrues to letterlevel processing from lexical-level feedback is considerably greater than the cost of distributing resources across both letter and lexical levels. Recently, Stolz and Besner (1998) demonstrated that activation of morphological information is also spared during letter search: Performing letter search on a prime word did not impair the priming of a morphologically related target word (e.g., REALREALITY Or SPEAK-SPOKE).

Hence, there is now considerable evidence that focusing attention at the letter level impairs semantic access but leaves both lexical and morphological access relatively unscathed. In the present study, we extend the investigation of the limiting effects of letter search to the realm of pictorial information. The question addressed here is whether letter search of a word impairs the activation of same-concept pictorial information. In other words, will performing letter search on the prime word CHAIR affect the priming of decisions about a picture of a chair?

On the right-hand side of Figure 1, a representational system for the processing of pictorial information is shown that parallels the representational system for words. According to this model, presentation of a picture initially activates a set of global features or geons (Biederman, 1987), which in turn activate object-level information in the pictogen (also referred to as the imagen by Johnson, Paivio, \& Clark, 1996, or the iconogen by Seymour, 1973), followed by the activation of conceptual information in the semantic system. As in the verbal system, there is also top-down feedback between levels. There is currently some debate about the level at which the verbal and pictorial systems are interconnected. Whereas some theorists have suggested that cross-modal activation results solely from activation at the semantic level-most typically through activation of a common, amodal conceptual representation (e.g., Hirshman, Snodgrass, Mindes, \& Feenan, 1990; Kroll \& Potter, 1984)others have argued that the verbal and pictorial systems are interconnected at earlier, presemantic levels. In particular, Paivio $(1971,1978)$ has suggested that there are direct connections between the lexicon and the pictogen such that activation of a word's lexical representation will in turn activate the corresponding pictogen representation, and vice versa (see Glaser, 1992, for an excellent review of theories of picture-word representation). In the present study, we address this debate by examining picture-word interactions in the absence or attenuation of semantic activation. More specifically, we investigate whether the activation of lexical information is sufficient to activate the same-concept picture representation when semantic activation is attenuated.

In these experiments, we employed the priming paradigm, in which a word prime was followed by a picture target. It has been known for some time that reading a word will facilitate the processing of a picture that corresponds to that word (e.g., the word CHAIR followed by a picture of a chair). For example, in an experiment by Durso and Johnson (1979), pictures (line drawings) and words were presented sequentially, and the subjects either read the words and named the pictures or categorized the stimuli as being natural or man-made by pressing certain keys. Priming conditions were created by repeating some of the stimulus concepts, either in the same modality (word-word or picture -picture) or between modalities (word-picture or picture-word). The condition of interest to us here is the one in which pictures were preceded by same-concept words. Both the 
naming and categorizing of pictures were facilitated following the processing of a same-concept word, thereby providing evidence that "a word trace contains information capable of aiding the processing of ... pictures" (Durso \& Johnson, 1979, p. 457). Given the model in Figure 1 , it is apparent that this facilitation could result from picture-word interactions either at the semantic level or between the lexicon and the pictogen. We differentiate between these two alternatives by making use of the fact that letter search through a prime word interferes with semantic processing but does not prevent lexical processing. Hence, facilitated processing of a picture target following letter search of a prime word would provide evidence for direct lexical-pictogen activation.

In Experiment 1, the prime was always a word, and the subjects performed one of two processing tasks-either letter search (Does this word contain a repeated letter?) or silent reading. The target was always a picture, which on half the trials represented the same concept as the word (e.g., the word CHAIR followed by a picture of a chair), or was unrelated to the prime. The subjects classified the picture as "living" or "nonliving," and the question of interest was whether picture classification would benefit from the prior presentation of the same-concept prime in the letter search condition. The rationale was as follows: Given that letter search of a prime prevents or attenuates activation of the prime's conceptual representation in the semantic system, and if words and pictures interact only at the conceptual level, the target picture will show little if any benefit. In other words, the subjects will be no faster at categorizing the target picture table following letter search of the word TABLE than following an unrelated word. On the other hand, greater priming of same-concept pictures would provide strong evidence that letter search did not prevent activation of the prime's pictorial representation at a presemantic level (i.e., of the pictogen).

\section{EXPERIMENT 1}

\section{Method}

Subjects. Fifty-six University of Toronto undergraduates participated as the subjects in this experiment, 22 in the silent read condition and 34 in the letter search condition.

Stimuli. The picture targets consisted of 40 line drawings selected from the Snodgrass and Vanderwart (1980) norms. The pictures were selected to meet two criteria, the first relating to their meaning (half the pictures represented living things, and half, nonliving things) and the second to their verbal label (half the names had repeated letters, such as ARROW and CLOCK, and half did not, such as CANDLE and FLOWER). The verbal labels were used as primes and the pictures as targets.

Presentation of the stimuli and the data collection were performed with software developed in MEL 1.0 language (Schneider, 1988 ). Pictures were digitized with $80 \times 80$ pixel images, and subtended a visual angle of approximately $4.3^{\circ} \times 3.5^{\circ}$. The prime word subtended an average visual angle of $2.1^{\circ} \times 0.5^{\circ}$

Procedure. The subjects were instructed to perform the prime and target tasks in rapid succession. Prime task was a between- subjects variable. For the subjects in the read condition, the prime word was presented for $1 \mathrm{sec}$ to be read silently. For the subjects in the letter search condition, the task was to decide whether or not the prime contained a repeated letter, and to indicate a choice by pressing the designated keys, "/" for "yes" or " $Z$ " for "no." The prime stayed on the screen until a keypress response was made, and it was immediately followed by the target. The target task was the same for both groups of subjects - to classify the picture as to whether it represented something that was living or nonliving by pressing the designated keys on the keyboard. The "yes" and "no" keys were the same as in the letter search task.

Each session consisted of 36 practice trials followed by 40 experimental trials. For half the trials, the prime and target represented the same concept (e.g., the word CHAIR followed by a picture of a chair), and for the other half, they were unrelated, formed by recombining the remaining word-picture pairs. Half the words contained a repeated letter, and half the pictures represented a living thing. There were equal numbers of each stimulus type (e.g., living-repeated) in the same-concept and unrelated conditions. Because of the difficulty in finding a sufficient number of pictures to meet both the semantic and the orthographic criteria, the practice set consisted of three repetitions of 12 picture-word pairs, each time in a different random order. None of the items used in the practice session were included in the experimental trials. Experimental items were presented only once, with each subject receiving a different random order. Across subjects, each picture appeared equally often in a matched (same-concept) format and in an unrelated format. As soon as the target response was made, the next trial began.

\section{Results}

In each of the experiments reported here, two analyses were performed on the reaction time (RT) data: one on the RTs trimmed to two standard deviations in each condition for each subject, and one on the inverse of the untrimmed RT, as suggested by Ratcliff (1993). Unless otherwise indicated, a significant effect was reliable by both tests. Trimmed means are presented in the tables, and presented $F$ values are based on these means. In Experiment 1 , approximately $1 \%$ of correct responses were trimmed and outliers were replaced by the cutoff value.

The mean letter search latency for the prime task was $1,240 \mathrm{msec}$, with a mean error rate of $8.4 \%$. The data of interest - namely, the time required to classify the pictures following either letter search or silent reading (collapsed across "yes" and "no" responses)-are shown in Table 1.

The classification times were slower following letter search $(1,034 \mathrm{msec})$ than following silent reading of the prime [ 803 msec; $F(1,39)=188.07, M S_{\mathrm{e}}=11,497, p<$ $.001]$, possibly because the picture appeared as soon as

Table 1

Mean Time (in Milliseconds) to Classify Pictures Following Silent Reading or Letter Search of the Prime Word, With Proportion Error, in Experiment

\begin{tabular}{lcccccc}
\hline & \multicolumn{4}{c}{ Condition } & \\
\cline { 2 - 3 } Prime Task & RT & E & & RT & E & Priming \\
\cline { 2 - 5 } \cline { 5 - 6 } Silent reading & 839 & .05 & 767 & .04 & 62 \\
Letter search & 1,069 & .06 & & 999 & .05 & 70 \\
\hline
\end{tabular}


the prime response was made in the letter search condition, whereas in the silent read condition there was time to prepare for the second stimulus. Alternatively, slower RTs following letter search may represent the additional time needed to shift attention from the orthographic level, at which letter search is conducted, to the semantic level, at which the picture classification task is performed. Presumably attention is already directed at the semantic level during silent reading. The effect of relatedness was also significant: Pictures were classified more rapidly when they represented the same concept as the word (matched) than when picture and word differed (were unrelated) $\left[F(1,39)=20.86, M S_{\mathrm{e}}=9,889, p<.001\right]$. More important, this facilitation for same-concept pairs was found in both prime processing conditions - the interaction between priming and task was not significant $(F<1)$. Analyses by items rather than by subjects yielded the same results. The finding that levels of priming were comparable in the letter search and silent read conditions was somewhat surprising, because as may be seen in Figure 1, following silent reading there are two possible loci of picture priming-one via the semantic system and one via lexical-pictogen transmission-whereas following letter search, the only source of activation is from the lexicon. Indeed, greater priming following silent reading was found in Experiment 2. None of the analyses of the error data approached significance.

\section{Discussion}

The results of this experiment are quite straightforward. Following letter search of a prime word, there is significant facilitation in the classification of a picture which represents the same concept as the word. Since letter search of the prime has previously been shown to attenuate semantic information, leaving lexical activation intact, we conclude that facilitation was not the result of conceptual priming in the semantic system, but resulted from a spread of activation from the prime word's lexical representation to its pictogen representation. Before accepting this conclusion, however, in the next experiment we examined the facilitation of picture targets semantically/associatively related to the prime word.

\section{EXPERIMENT 2}

Whereas the repetition priming of pictures that represent the same concept as a preceding word prime could in theory result from processes occurring at presemantic levels (such as a spread of activation from the lexicon to the pictogen), semantic priming depends on processes occurring at the semantic level. In addition to the extensive literature on the semantic priming of word targets by semantically/associatively related word primes (see Neely, 1991, for a review), several studies have demonstrated the semantic priming of picture targets following the processing of semantically/associatively related word primes - studies demonstrating that presentation of the word CAT, for example, facilitates the subsequent processing of a picture of a dog. Picture priming has been found to occur following a variety of word prime processing tasks, including naming, silent reading, and categorization, and has been demonstrated for both the categorization and the naming of picture targets. For example, Sperber, McCauley, Ragain, \& Weil (1979), using a task in which words and pictures were instances of the same superordinate category, found facilitated picture categorization following the categorization of a samecategory word. Irwin and Lupker (1983) similarly found priming of picture categorization following a task in which the prime word was named. In a study by Bajo (1988), in which stimulus pairs that either were associatively related (e.g., CAT-DOG) or were members of the same category (e.g., NOSE-EYE), subjects silently read a prime word for $1 \mathrm{sec}$ and then performed one of two target processing tasks: name verification (Does the name of the picture match the name of an orally presented concept?) or category verification (Does the picture belong to an orally presented category?). Both name and category verification of the picture targets were facilitated by the prior presentation of a related word prime. In several studies, facilitated naming of a picture target has been found following either the silent reading of a related word prime (e.g., Bajo \& Canas, 1989; La Heij, Dirkx, \& Kramer, 1990; Lupker, 1988) or the overt naming of a word prime, even under conditions in which the prime response was not made until after the target had been named, in order to keep the stimulus onset asynchrony brief (Carr, McCauley, Sperber, \& Parmalee, 1982; McCauley, Parmalee, Sperber, \& Carr, 1980).

Such studies provide ample evidence that picture processing is facilitated by the prior processing of a semantically related word under normal word reading conditions-where the word is read as a whole. In Experiment 1, letter search of the prime did not interfere with the categorization of a picture that represented the same concept as did the prime. Since same-concept priming may not depend on activation of the semantic system, the observed cross-modal facilitation could be interpreted as providing evidence that letter search does not interfere with lexical-pictogen activation. However, since letter search disrupts semantic activation, we would not expect to find semantic priming of picture targets following the letter search of semantically/associatively related word primesa process presumed to occur in the semantic system.

To investigate this issue, we included an additional condition in Experiment 2-a condition in which wordpicture pairs were semantically related (e.g., the word CHAIR followed by a picture of a table). In this experiment there were two conditions, one in which half the pairs represented the same concept (repetition priming), and one in which half the pairs were semantically related (semantic priming). 


\section{Method}

Subjects. Participants in this study were 128 University of Toronto undergraduates, 64 in the letter search condition and 64 in the silent read condition.

Stimuli. Two lists of 58 pictures each were selected from the Snodgrass and Vanderwart (1980) norms, with the proviso that half the picture names must contain a repeated letter and half must not. In each list, 40 of the pictures represented man-made items, such as BOOK or JACKET, and 18 represented things that were not man-made, such as EYE, ONION, or SKUNK.

Procedure. The subjects in each of the prime processing conditions were given two blocks of trials, one in which half the pairs represented the same concept (repetition priming), and a second in which half the pairs were conceptually related (semantic priming). The same set of pictures was used in the two blocks. There were 58 trials for each condition. Order of presentation of blocks was counterbalanced across the subjects, with half the subjects receiving the block of same-concept pairs first and half receiving the block of semantically related pairs first. Assignment of lists to condition (repetition/semantic) and of items to list (related/unrelated) was totally balanced. The procedure was the same as in Experiment 1, with three minor changes: First, the picture classification task was changed to "Is this item man-made?" (rather than "living-nonliving"). Second, to better equate the letter search and read conditions, the subjects were required to make a response to the prime in both conditions, and prime presentation was always response terminated. In the letter search condition, the subjects were to respond "yes" or "no" as in Experiment 1, and in the read condition they were to press the "/" key as soon as they had silently read the word. The target immediately followed prime offset. Finally, the intertrial interval was extended to $1 \mathrm{sec}$, because the subjects had reported feeling rushed in Experiment 1.

\section{Results}

The mean times to silently read the prime were $514 \mathrm{msec}$ in the same-concept condition and $534 \mathrm{msec}$ in the semantically related condition. The mean letter search times were $836 \mathrm{msec}$ for the block in which prime and target represented the same concept, with $4.4 \%$ errors, and $879 \mathrm{msec}$ in the block in which they were semantically related, with $6.7 \%$ errors. RT values did not differ significantly in the two blocks $(F<1)$, but the difference in error rates was reliable $\left[F(1,63)=23.8, M S_{\mathrm{e}}=0.0027, p<\right.$ $.01]$. There was a significant effect of practice, with the subjects performing the prime task faster when it was presented in the second block of trials rather than the first $\left[F(1,126)=164.02, M S_{\mathrm{e}}=20,613, p<.001\right]$. The effect of practice was even greater for letter search (149 msec) than for silent reading $(81 \mathrm{msec})\left[F(1,126)=14.4, M S_{\mathrm{e}}=\right.$ $20,613, p<.001]$.

The RTs and error rates for the picture classification task are presented in Table 2. Using the same procedure as in Experiment $1,0.7 \%$ of responses were trimmed and outliers were replaced with the cut-off value. As in Experiment 1 , the subjects classified the target more rapidly following silent reading than following letter search $\left[F(1,126)=11.4, M S_{\mathrm{e}}=130,963, p<.01\right]$, despite the fact that in Experiment 2 a prime response was required in the read condition as well as in the letter search condition, with target presentation immediately following the prime response in both conditions. The RTs were considerably shorter in this experiment than in Experiment 1, both for letter search of the primes and for classification of the picture targets. The introduction of the 1 -sec intertrial interval (ITI) in this experiment, which slowed the pace of the experiment itself, may have given the subjects more time to prepare. A second factor is the effect of practice: There were 116 trials in Experiment 2, whereas there were only $\mathbf{4 0}$ trials in Experiment 1, and each stimulus in this experiment appeared twice-once in the same-concept block and once in the semantically related block. The effect of practice was significant, with faster picture classification in the second block of trials than in the first block $\left[F(1,126)=318.2, M S_{\mathrm{e}}=13,625\right.$, $p<.001]$. This effect of practice was greater for trials following letter search of the prime $(146 \mathrm{msec})$ than following silent reading of the prime $(114 \mathrm{msec})[F(1,126)=$ 4.7, $\left.M S_{\mathrm{e}}=13,625, p<.03\right]$. The effect of practice did not enter significantly into any other interactions and did not affect error rate. Consequently, the presented data are collapsed across the two runs.

The main effect of priming was reliable, with faster responses in the related condition than in the unrelated condition $\left[F(1,126)=46.97, M S_{\mathrm{e}}=2,377, p<.01\right]$. The interaction of priming and type of relatedness was also significant $\left[F(1,126)=22.4, M S_{\mathrm{e}}=2,156, p<.01\right]$, with more facilitation when the prime and the target represented the same concept than when they were semantically related. Whereas repetition priming is typically greater than semantic priming when the prime and the target are both words, the present results extend this finding to the condition in which the prime is a word and

Table 2

Mean Reaction Times (RT, in Milliseconds) and Proportion Error to Classify Pictures Following Silent Reading or Letter Search of Same-Concept Prime Word (Repetition Priming) or of Related Prime Word (Semantic Priming) in Experiment 2

Word-Picture Relationship

\begin{tabular}{|c|c|c|c|c|c|c|c|c|c|c|}
\hline \multirow[b]{3}{*}{ Task } & \multicolumn{5}{|c|}{ Repetition Priming } & \multicolumn{5}{|c|}{ Semantic Priming } \\
\hline & \multicolumn{2}{|c|}{ Unrelated } & \multicolumn{2}{|c|}{ Related } & \multirow[b]{2}{*}{ Priming } & \multicolumn{2}{|c|}{ Unrelated } & \multicolumn{2}{|c|}{ Related } & \multirow[b]{2}{*}{ Priming } \\
\hline & $\mathrm{RT}$ & $\mathrm{E}$ & RT & $\mathrm{E}$ & & RT & $E$ & RT & E & \\
\hline Silent reading & 646 & .03 & 600 & .03 & $46 \dagger$ & 650 & .04 & 635 & .03 & $15^{*}$ \\
\hline Letter search & 724 & .04 & 701 & .04 & $23 \dagger$ & 705 & .03 & 706 & .03 & -1 \\
\hline
\end{tabular}


the target is a picture, thereby ruling out orthographic factors as the sole basis for greater repetition than semantic priming. The interaction of priming and prime processing task was also significant: Picture categorization was facilitated to a greater extent following silent reading than following letter search $\left[F(1,126)=10.5, M S_{\mathrm{e}}=\right.$ $2,377, p<.01]$. The three-way interaction of priming $\times$ type $\times$ task was not reliable $(F<1)$.

This pattern of results can be readily explained by the assumption that there are two components of priming, one that operates via the semantic system and a second that operates via the lexical-pictogen system. During silent reading, both components are operative. However, the effect of letter search is to reduce or eliminate the semantic component, leaving only the lexical-pictogen component operative. Elimination of the semantic component has differential effects on repetition and semantic priming. In the repetition priming condition, facilitation of picture processing can still occur via lexical-pictogen transmission, although it is not as great as in the silent read condition [ 23 vs. $46 \mathrm{msec} ; F(1,126)=6.7, M S_{\mathrm{e}}=$ $2,618, p<.01]$. In contrast, since the only source of picture facilitation in the semantic condition occurs via the semantic component, there is no semantic priming of pictures following letter search of the prime. This interpretation is supported by an analysis of critical differences, which indicated that in the repetition priming condition there was reliable priming in both the silent read and the letter search conditions $\left[F(1,126)=52.4, M S_{\mathrm{e}}=10,473\right.$, $p<.001$, and $F(1,126)=12.9, M S_{\mathrm{e}}=10,473, p<.001$, respectively]. However, in the semantic priming condition there was reliable priming only following silent reading of the prime word $\left[F(1,126)=7.7, M S_{\mathrm{e}}=7,661\right.$, $p<.01]$. There was no semantic priming at all following letter search $(-1 \mathrm{msec})$. Error rates did not differ significantly across conditions. Analyses by items rather than by subjects yielded comparable results.

\section{Discussion}

The first important finding of this experiment is that even with a somewhat different set of stimuli and responses from those employed in Experiment 1, and although overall RTs were considerably faster, the main result of Experiment 1 was replicated: There was significant repetition priming of pictures preceded by same-concept word primes, even when subjects performed letter search of the prime. It should be noted, however, that whereas the magnitude of repetition priming was the same in both the letter search and the silent read conditions in Experiment 1, in Experiment 2 repetition priming was greater in the silent read condition. One possible explanation for this difference will be suggested in the General Discussion.

The second important finding is that there was no priming of pictures that followed letter search of semantically related word primes. Previous studies have demonstrated that there is no semantic priming of word targets, and in Experiment 2 that result was extended to picture targets. The absence of semantic priming, which is dependent on processes in the semantic system, helps to localize repetition priming of same-concept pictures to presemantic levels.

Although we believe that the priming of pictures following letter search of same-concept word primes is convincing evidence that letter search does not block the spread of activation between the lexical and pictogen representational systems, it could be argued that the observed priming is the result of a particular strategy that subjects adopt: In the repetition priming condition, recognizing that half the pictures represented the same concept as the word, the subjects may have adopted the strategy of making the "living-nonliving" decision to the prime word prior to target onset; that is, in addition to letter search, the subjects also categorized the prime. Hence, on sameconcept trials, picture categorization was completed prior to target onset, resulting in faster RTs. However, examination of the letter search times in the same-concept and in the semantically related conditions makes this argument unlikely. The letter search times did not differ in the repetition and the semantic priming blocks, suggesting that the subjects were not taking extra time following letter search in the same-concept condition to also make the "living-nonliving" decision. If comparable prime RTs occurred because the subjects were also employing this strategy in the semantically related condition, priming should have been found in the semantically related condition as well. The demonstration of sameconcept priming but not of related-concept priming, with comparable letter search times in the two conditions, argues against this particular strategic explanation for same-concept priming.

\section{GENERAL DISCUSSION}

The results of these experiments extend our understanding of the modulation of activation when attention is focused at the letter level during word recognition. Whereas previous experiments have demonstrated that focusing attention at the letter level does not prevent activation of the word's lexical or morphological representations, the present study demonstrates that it also does not prevent activation of its pictogen representation.

Although focusing at the letter level does not prevent activation of a word's lexical representation, it clearly modulates semantic activation. This conclusion is based on the consistent demonstration, in earlier experiments with words and in the present study with pictures, that there is no facilitation of target processing following letter search of a semantically/associatively related prime. The simplest explanation for this finding is that in contrast to ordinary word reading, where most available resources are allocated to lexical and semantic processing, most of the processing resources are allocated to the letter level when letter search is required. Some indirect support for this conclusion comes from the slower pic- 
ture categorization times following letter search than following silent reading. Whereas attention may be assumed to be focused at the semantic level during both silent reading and picture categorization, following letter search attention must shift from the orthographic system to the semantic system, thereby adding to the response time.

Although the present study does not permit us to determine whether the attenuation of semantic activation during letter search operates in an all-or-none fashion, an experiment in which Henik et al. (1994) manipulated the proportion of semantically related trials within the stimulus list suggests that it does not. When only $20 \%$ or $50 \%$ of the pairs were related, there was no semantic priming of lexical decision following letter search of the prime. However, priming did occur when $80 \%$ of the pairs were related. These results point to considerable flexibility in the allocation of attentional resources. When the semantic relatedness between prime and target is emphasized, as in the $80 \%$ condition, more attention is allocated to the semantic level of processing, even if letter search is required for the prime. Unfortunately, no data were reported concerning performance on the prime processing task to see how allocation of attention to the semantic level influenced performance at the orthographic level. A further demonstration of the flexibility of resource allocation in letter search is provided by Stolz and Besner (1997), who found preserved semantic priming of lexical decision following letter search of a related prime if the subjects were given a brief preview of the prime word prior to the letter search task. In the present paper, the finding that magnitude of repetition priming was comparable in the letter search and silent read conditions in Experiment 1, but greater following silent reading than following letter search in Experiment 2, may be a further manifestation of this flexibility. Because there was no time to switch from the semantic level to the orthographic level in Experiment 1 following picture categorization (recall that the ITI was zero), the subjects may have maintained some attention at the semantic level even during letter search. Studies of task switching indicate that when the ITI is very brief, leaving little time to switch attention between two consecutive tasks, subjects may attempt to monitor both tasks in parallel, rather than switch between them (e.g., Meiran \& Daichman, 1998; Rogers \& Monsell, 1995). This division of attention could explain the fact that latency of responding, both for letter search of the prime and for categorization of the target, was considerably slower in Experiment 1 than in Experiment 2, where the introduction of the 1-sec ITI provided sufficient time to switch attention between levels.

We have suggested in this paper that the preservation of repetition priming in the absence of semantic priming following letter search in the prime results from the allocation of attention to the orthographic level at the expense of semantic processing. However, an alternative possibility is that focusing attention at the letter level does not interfere with activation of the semantic system per se, but rather with the activation of conceptually related representations within the semantic system. In other words, it could be argued that the prime's conceptual representation is activated even during letter search, and that what letter search does is prevent the spread of activation to conceptually related units within the semantic system. Clearly, such an explanation would be incompatible with a connectionist model of semantic representation in which semantic priming results from the overlap of semantic features and not from a spread of activation between related representations (see, e.g., Masson, 1991). Further, a study by Friedrich et al. (1991) argues against this possibility. In one condition (Experiment 4), the prime word was presented auditorily as well as visually, thereby guaranteeing activation of the prime's semantic representation. In this condition, the requirement of doing letter search on the prime did not interfere with semantic priming. These data suggest that letter search has its effect by interfering with access to the semantic system, rather than by blocking the activation of related concepts within the semantic system.

Although we interpret our data as providing support for a lexical-pictogen connection that is not dependent on semantic activation, we acknowledge that these experiments do not unequivocally rule out the possibility of a semantic locus for the repetition priming of pictures. In this scenario, picture priming is the result of activation in the semantic system of an amodal conceptual representation. During letter search, activation of this representation is attenuated. Although the resulting activation is still sufficient to support repetition priming, there is insufficient activation to support the priming of related concepts-either through loss of activation during the spread to related concepts, or because of reduced feature activation of semantically related concepts. Although we cannot rule out this interpretation, the large number of previous demonstrations showing a total absence of semantic priming of words following letter search of the prime, and the present finding that there is no semantic priming of pictures following letter search, leads us to prefer the explanation that when attention is focused at the letter level, there is little, if any, activation of the semantic system. Consequently, repetition priming of sameconcept pictures is best interpreted in terms of a flow of activation between the lexical and pictogen levels of representation.

In conclusion, the present study extends the investigation of the way in which explicit processing at the letter level modulates activation during word recognition. Whereas previous studies have demonstrated that performing letter search on a prime word impairs semantic activation without preventing lexical or morphological activation, here we demonstrate that it does not prevent activation of nonverbal, pictorial information. This result should be of particular interest to cognitive neuropsychologists, for we are not aware of any existing cog- 
nitive neuropsychological evidence of such "cross-talk" between linguistic and pictorial subsystems in the absence of semantic mediation.

\section{REFERENCES}

Anderson, J. R. (1976). Language, memory, and thought. Hillsdale, NJ: Erlbaum.

ANDERSON, J. R. (1983). The architecture of cognition. Cambridge, MA: Harvard University Press.

BAJo, M. T. (1988). Semantic facilitation with pictures and words. Journal of Experimental Psychology: Learning, Memory, \& Cognition, 14, 579-589.

Bajo, M. T., \& CANaS, J. J. (1989). Phonetic and semantic activation during picture and word naming. Acta Psychologica, 72, 105-1 15.

Bentin, S., Smith, M. C., \& Spalek, T. (1997, November). Automatic semantic activation following letter search of the prime. Paper presented at the annual meeting of the Psychonomic Society, Philadelphia.

Besner, D., Smith, M. C., \& MacLeod, C. M. (1990). Visual word recognition: A dissociation of lexical and semantic processing. Journal of Experimental Psychology: Learning, Memory, \& Cognition, 16, 862-869.

BIEDERMAN, I. (1987). Recognition-by-components: A theory of human image understanding. Psychological Review, 94, 115-145.

Carr, T. H., McCauley, C., Sperber, R. D., \& Parmalee, C. M. (1982). Words, pictures, and priming: On semantic activation, conscious identification, and the automaticity of information processing. Journal of Experimental Psychology: Human Perception \& Performance, 8,757-777.

Chiarello, C., Burgess, C., Richardos, L., \& Pollock, A. (1990). Semantic and associative priming in the cerebral hemispheres: Some words do, some words don't ... sometimes, some places. Brain \& Language, 38, 75-104.

Chiarello, C., \& Richards, L. (1992). Another look at categorical priming in the cerebral hemispheres. Neuropsychologia, 30, 381-392.

Coluins, A. M., \& LofTus, E. F. (1975). A spreading-activation theory of semantic processing. Psychological Review, 82, 407-428.

Durso, F. T., \& Johnson, M. K. (1979). Facilitation in naming and categorizing repeated pictures and words. Journal of Experimental Psychology: Human Learning \& Memory, 5, 449-459.

FisCHLER, I. (1977). Semantic facilitation without association in a lexical decision task. Memory \& Cognition, 5, 335-339.

Friedrich, F. J., Henik, A., \& Tzelgov, J. (1991). Automatic processes in lexical access and spreading activation. Journal of Experimental Psychology: Human Perception \& Performance, 17, 792-806.

Glaser, W. R. (1992). Picture naming. Cognition, 42, 61-105.

Henik, A., Friedrich, F. J., \& Kellogg, W. A. (1983). The dependence of semantic relatedness effects upon prime processing. Memory \& Cognition, 11, 366-373.

henik, A., Friedrich, F. J., Tzelgov, J., \& Tramer, S. (1994). Capacity demands of automatic processes in semantic priming. Memory \& Cognition, 22, 157-168.

Hines, D., Czerwinski, M., Sawyer, P. K., \& Dwyer, M. (1986). Automatic semantic priming: Effect of category exemplar level and word association level. Journal of Experimental Psychology: Human Perception \& Performance, 12, 370-379.

Hirshman, E., Snodgrass, J. G., Mindes, J., \& Feenan, K. (1990). Conceptual priming in fragment completion. Experimental Psychology: Learning, Memory, \& Cognition, 16, 634-647.

HofFMAN, J. E., \& MacMillan, F. W. (1985). Is semantic priming automatic? In M. I. Posner \& O. S. M. Marin (Eds.), Attention and performance $X I$ (pp. 585-599). Hillsdale, NJ: Erlbaum.

IRWIN, D. I., \& LUPKER, S. J. (1983). Semantic priming of pictures and words: A levels of processing approach. Journal of Verbal Learning \& Verbal Behavior, 22, 45-60.

Johnson, C. J., Paivio, A., \& Clark, J. M. (1996). Cognitive components of picture naming. Psychological Bulletin, 120,113-139.

Kahneman, D. (1973). Attention and effort. Englewood Cliffs, NJ: Prentice-Hall.

KAYE, D. B., \& BRown, S. W. (1985). Levels and speed of processing effects on word analysis. Memory \& Cognition, 13, 425-434.
Kroll, J. F., \& PotTer, M. C. (1984). Recognizing words, pictures, and concepts: A comparison of lexical, object, and reality decisions. Journal of Verbal Learning \& Verbal Behavior, 23, 39-66.

Krueger, L. E., \& Weiss, M. E. (1976). Letter search through words and nonwords: The effect of fixed, absent, or mutilated targets. Memory \& Cognition, 4, 200-206.

La HeIJ, W., Dirkx, J., \& Kramer, P. (1990). Categorical interference and associate priming in picture naming. British Journal of Psychology, 81, 511-525.

Lund, K., Burgess, C., \& Atchley, R. A. (1995). Semantic and associative priming in high-dimensional semantic space. In Proceedings of the Annual Conference of the Cognitive Science Society (pp. 660665). Hillsdale, NJ: Erlbaum.

LUPKER, S. J. (1984). Semantic priming without association: A second look. In Journal of Verbal Learning \& Verbal Behavior, 23, 709-733.

LUPKER, S. J. (1988). Picture naming: An investigation of the nature of categorical priming. Journal of Experimental Psychology: Learning. Memory, \& Cognition, 14, 444-455.

Masson, M. E. J. (1991). A distributed memory model of context effects in word identification. In D. Besner \& G. Humphreys (Eds.), Basic processes in reading: Visual word recognition (pp. 233-263). Hillsdale, NJ: Erlbaum.

McCauley, C., Parmalee, C. M., Sperber, R. D., \& Carr, T. H. (1980). Early extraction of meaning from pictures and its relation to conscious identification. Journal of Experimental Psychology: Human Perception \& Performance, 6, 265-276.

McClelland, J. L., \& RumelharT, D. E. (1981). An interactiveactivation model of context effects in letter perception: Part 1. An account of basic findings. Psychological Review, 88, 375-407.

Meiran, N., \& Daichman, A. (1998, September). Parallel processing of tasks in the task switching paradigm: Evidence from error analysis. Paper presented at the 10th conference of the European Society for Cognitive Psychology, Jerusalem.

Moss, H. E., Ostrin, R. K., Tyler, L. K., \& Marslen-Wilson, W. D. (1995). Accessing different types of lexical semantic information: Evidence from priming. Journal of Experimental Psychology: Learn ing, Memory, \& Cognition, 21, 863-883.

NAVON, D., \& Gopher, D. (1979). On the economy of the human processing system. Psychological Review, 86, 214-253.

NeELy, J. H. (1991). Semantic priming effects in visual word recognition: A selective review of current findings and theories. In D. Besner \& G. Humphreys (Eds.), Basic processes in reading: Visual word recognition (pp. 264-336). Hillsdale, $\mathrm{NJ}$ : Erlbaum.

NeELY, J. H., \& KeEFE, D. E. (1989). Semantic context effects on visual word processing: A hybrid prospective/retrospective processing theory. In G. H. Bower (Ed.), The psychology of learning and motiva tion: Advances in research and theory (Vol. 24, pp. 207-248). New York: Academic Press.

PAIvio, A. (1971). Imagery and verbal processes. Hillsdale, NJ: Erlbaum. PaIvio, A. (1978). A dual coding approach to perception and cognition. In H. L. Pick, Jr., \& E. Saltzman (Eds.), Modes of perceiving and processing information (pp. 39-51). Hillsdale, NJ: Erlbaum.

POSNER, M. I., \& SNYDER, C. R. R. (1975). Attention and cognitive control. In R. L. Solso (Ed.), Information processing and cognition: The Loyola symposium (pp. 55-83). Hillsdale, NJ: Erlbaum.

RATCLIFF, R. (1993). Methods for dealing with reaction time outliers. Psychological Bulletin, 114, 510-532.

RaTCLIFF, R., \& MCKoON, G. (1997). A counter model for implicit priming in perceptual word identification. Psychological Review, 104, 319-343.

ROGERS, R. D., \& MONSELL, S. (1995). The cost of a predictable switch between simple cognitive tasks. Journal of Experimental Psychology: General, 124, 207-231.

SCHNEIDER, W. (1988). Micro Experimental Laboratory: An integrated system for IBM PC compatibles. Behavior Research Methods, Instruments, \& Computers, 20, 206-217.

Schreuder, R., Flores d' Arcais, G. B., \& Glanzenborg, G. (1984) Perceptual and conceptual similarity effects in semantic priming. Psychological Research, 45, 339-354.

Seidenberg, M. S., Waters, G. S., Sanders, M., \& Langer, P. (1984) Pre- and postlexical loci of contextual effects on word recognition. Memory \& Cognition, 12, 315-328. 
SEymour, P. H. K. (1973). A model for reading, naming, and comparison. British Journal of Psychology, 64, 35-49.

SMITH, M. C. (1979). Contextual facilitation in a letter search task depends on how the prime is processed. Journal of Experimental Psychology: Human Perception \& Performance, 5, 239-251.

Smith, M. C., Meiran, N., \& Besner, D. (1996). When is a direct test of memory more sensitive than an indirect test? Canadian Journal of Psychology, 50, 139-148.

Smith, M. C., Theodor, L., \& Franklin, P. E. (1983). The relationship between contextual facilitation and depth of processing. Journal of Experimental Psychology: Learning, Memory, \& Cognition, 9, 697-712.

SnODGRass, J. G., \& VANDERWART, M. (1980). A standardized set of 260 pictures: Norms for name agreement, image agreement, familiarity, and visual complexity. Journal of Experimental Psychology: Human Learning \& Memory, 6, 174-215.
Sperber, R. D., McCauley, C., Ragain, R. D., \& Weil, C. M. (1979). Semantic priming effects on picture and word processing. Memory \& Cognition, 7, 339-345.

STOLZ, J. A., \& BESNER, D. (1997). Visual word recognition: Effort after meaning but not (necessarily) meaning after effort. Journal of Experimental Psychology: Human Perception \& Performance, 23, 1314-1322.

Stolz, J. A., \& BeSNER, D. (1998). Levels of representation in visual word recognition: A dissociation between morphological and semantic processing. Journal of Experimental Psychology: Human Perception \& Performance, 24, 1642-1655.

(Manuscript received July 16, 1998; revision accepted for publication February 10, 1999.) 